van der Horst, G., Medger, K., Steckler, D., Luther, I., Bartels, P. 2018. Bottlenose dolphin (Tursiops truncatus) sperm revisited: Motility, morphology and ultrastructure of fresh sperm of consecutive ejaculates. Animal Reproduction Science 195: 309-320. Doi: 10.1016/j.anireprosci.2018.06.009

\title{
Bottlenose dolphin (Tursiops truncatus) sperm revisited: Motility, morphology and ultrastructure of fresh sperm of consecutive ejaculates
}

Gerhard van der Horst ${ }^{\mathrm{a} \mathrm{b}^{\mathrm{k}}}$, Katarina Medger ${ }^{\mathrm{c}}$, Daniela Steckler ${ }^{\mathrm{d}}$, Ilse Luther ${ }^{\mathrm{e}}$ and Paul Bartels $^{\dagger}$

aUniversity of the Western Cape, Private Bag X17, Bellville 7535, South Africa, gvdhorst7@gmail.com

${ }^{\mathrm{b}}$ National Zoological Gardens of South Africa, 232 Boom Street, Pretoria 0001, South Africa

'Department of Zoology and Entomology, University of Pretoria, Hatfield/Pretoria 0028, South Africa, kmedger@zoology.up.ac.za

dSection of Reproduction, Faculty of Veterinary Science, University of Pretoria, Onderstepoort, Pretoria 0110, South Africa, daniela-steckler@gmx.de 'GEOsperm, Brits 0250, South Africa, ilseluther@gmail.com

fDepartment of Nature Conservation, Tshwane University of Technology, Pretoria-West 0001, South Africa, bartpaul@gmail.com

*Corresponding author: Gerhard van der Horst; Department of Medical Biosciences, University of the Western Cape, Private Bag X17, Bellville, 7530, South Africa; Tel: (+27-21) 959 2183; Fax: (27 21) 959 1377; Email: gvdhorst7@gmail.com

(C) 2018. This manuscript version is made available under the CC-BY-NC-ND 4.0 license http://creativecommons.org/licenses/by-nc-nd/4.0/ 


\section{ABSTRACT}

Computer aided sperm analysis systems allow detailed examination of sperm motility and morphology variables, which are important for the understanding of the spermatology of a species and the development of assisted reproductive techniques. Cetacean biology is complex to study in the wild and data from captive individuals provide an important alternative for the conservation of these charismatic animals. The present study evaluates ejaculate and sperm characteristics, including sperm motility, kinematic parameters and quantitative sperm morphology and ultrastructure, of consecutive ejaculates from Atlantic bottlenose dolphins (Tursiops truncatus). Sperm concentrations and total and progressive motilities were greater in the second than the first ejaculate, with all ejaculates being of very high quality $\left(6.9-1127 \times 10^{6} / \mathrm{ml} \mathrm{sperm}\right.$ concentration, $75 \%$ to $91 \%$ total motility and $89 \%$ to $96 \%$ normal sperm). Most sperm in an ejaculate ( $\geq 84 \%)$ were highly (VCL $>150 \mu \mathrm{m} / \mathrm{s})$ and progressively motile with very few abnormal sperm. The sperm have small heads, a short but very bulky midpiece and a long tail. Detailed sperm morphometrics using CASA indicated there were similarities from one ejaculate to the next. The large mitochondria with extensive cristae mitochondriales are tightly packed in the midpiece resulting in a large midpiece volume. All the semen and sperm characteristics indicate high quality sperm and support the assumption that a multimale mating system is present in T. truncatus.

Keywords: Atlantic bottlenose dolphin; Tursiops truncatus; CASA; Sperm kinematics; Sperm speed; Sperm morphometrics

(C) 2018. This manuscript version is made available under the CC-BY-NC-ND 4.0 license http://creativecommons.org/licenses/by-nc-nd/4.0/ 


\section{Introduction}

Most cetaceans are threatened and all species are listed in Appendix II of CITES as populations face a number of threats among which are commercial hunting, incidental captures in fisheries and habitat degradation (Reeves et al., 2003). The nature of the cetacean habitat makes it extremely difficult to study these animals and makes captive populations especially valuable for research of their biology (O'Brien and Robeck, 2010b). Due to ethical considerations cetaceans, however, are becoming rarer in captivity, which makes it more difficult to obtain material and data and makes any information exceedingly valuable for cetacean research.

Exchange of cetaceans between captive facilities is problematic because of the risks and regulations involved (O'Brien and Robeck, 2010b)., Accordingly, sperm cryopreservation and artificial insemination ( $\mathrm{Al}$ ) methods, have been developed for a number of cetacean species (Robeck and O'Brien, 2004; Robeck et al., 2004; O'Brien et al., 2008; Robeck et al., 2009; O'Brien and Robeck, 2010a), ; ).

A thorough understanding of the basic semen and sperm variables of a species is essential. Sperm quality varies not only between individuals of the same species, but also between consecutive ejaculates of the same individual. In some mammals a reduction in semen volume and sperm concentration was observed from the first to subsequent ejaculates (Ritar et al., 1992; Ambriz et al., 2002). In contrast, some aspects of sperm quality were greater in the second ejaculate of both Indo-Pacific (Tursiops aduncus) and Atlantic bottlenose dolphins (Yuen et al., 2009; SánchezCalabuig et al., 2015). Fresh Atlantic bottlenose dolphin ejaculates are in general of very high quality with excellent sperm motilities, little sperm DNA fragmentation and few abnormal sperm (Fleming et al., 1981; O'Brien and Robeck, 2006; Montano et al., 2012; Sánchez-Calabuig et al., 2015).

The present study evaluated macro and micro sperm characteristics (sperm motilities and kinematics) of fresh ejaculates from three sexually mature Atlantic bottlenose dolphins using a computer aided sperm analysis (CASA) system. We hypothesized that subsequent ejaculates would be of greater quality than first ejaculates

(C) 2018. This manuscript version is made available under the CC-BY-NC-ND 4.0 license http://creativecommons.org/licenses/by-nc-nd/4.0/ 
and as such would be a more reliable indicator of a dolphins' reproductive capacity as well as have greater value for ART. Results from three recent studies in humans indicate that the second ejaculate collected a few hours after the first yielded sperm with greater functional characteristics (Alipour et al., 2017; Ayad et al., 2018a, 2018b). The main reason appears to be that sperm age very quickly in the cauda epididymis and sperm from subsequent ejaculates would have been stored in vivo for less time and as such be of greater quality. Moreover, in species with greater amounts of sperm competition it will be advantageous that sperm are of high quality in consecutive ejaculates. This is the first study where this aspect has been quantified by CASA. The present study also complimented previous studies that focused on sperm motility through assessment of sperm sub-populations (rapid, medium and slow). This aspect has not been sufficiently addressed in the past assuming that averages of kinematic values represent the fertilizing sperm population. Eleven sperm morphometric features of the sperm head as well as tail and midpiece length, using CASA was measured for the first time, and evaluation of ultrastructural features by means of transmission electron microscopy. Data collected in the present study provided further and more comprehensive quantitative information and knowledge on the association of semen and sperm characteristics. Many of the aspects addressed in the current study have been published, but because of the small numbers of dolphins used in all these previous studies, including some from our laboratory, it is important to further assess and establish similarities, differences and potential shortcomings.

\section{Materials and methods}

\subsection{Research animals}

Two Atlantic bottlenose dolphins, Tursiops truncatus, (henceforth referred to as TT1 and TT2) and a truncatus-male/aduncus-female hybrid (TA1) of uShaka Marine World, Durban, South Africa were trained for semen collection. Conditioning of the dolphins to the voluntary semen collection took approximately 3 weeks. The age of the dolphins varied from 18 (TA) to more than 32 years (TT1) and both TT1 and TT2 successfully sired offspring. Ethical clearance for this project was granted by uShaka

(C) 2018. This manuscript version is made available under the CC-BY-NC-ND 4.0 license http://creativecommons.org/licenses/by-nc-nd/4.0/ 
Marine World, Durban, South Africa as well as by the Research Ethics and Scientific Committee of the National Zoological Gardens of South Africa (RESC/P06/34).

\subsection{Semen collection}

Part of the conditioning involved that the dolphins presented themselves with the ventral side up and the trainer tapping lightly by hand on the abdominal wall in front of the sheath that surrounds the penis. This resulted in an erect penis being exposed and it was possible to rapidly rinse the penis with $0.9 \%$ saline to exclude potential contamination with sea water. After rinsing the penis, a sterile plastic bag was placed over the erect penis which was in all cases followed by ejaculation. The semen was immediately removed from the plastic bag and the volume measured in Falcon tubes to the closest $\mathrm{mL}$. Semen color and viscosity were also estimated using a subjective manual scale and a rough estimate of $\mathrm{pH}$ was performed using Panpeha $\mathrm{pH}$ paper strips (Whatman, GE Healthcare Life Sciences, UK). These aspects constituted the macro semen/sperm characteristics. Consecutive ejaculates (three) were sampled at 30 minute intervals and repeated after 24 hours.

\subsection{Sperm concentration and sperm motility (micro sperm characteristics)}

The sperm concentration and motility module of the Sperm Class Analyzer (SCA) version 4.1 (Microptic SL, Barcelona, Spain) was used to determine sperm concentration, the percentage sperm motility, progressive sperm motility and sperm kinematics (see Table 2 for more details). For sperm concentration semen was diluted from 1:20 and up to 1:100 using Ham's F10 culture medium (Gibco laboratories, Buffalo, USA). The diluted sperm suspension was introduced in a Leja $20 \mu \mathrm{m}$ deep chamber (Leja Products, The Netherlands). An Olympus CH2 microscope with negative phase optics (x10 objective) and a temperature controlled stage $\left(37^{\circ} \mathrm{C}\right)$ was used in conjunction with a Basler 312FC firewire camera. The sperm concentration was determined using the SCA system calibrated for this Leja chamber. At least three different microscopic fields were used counting at least 500 motile sperm.

(C) 2018. This manuscript version is made available under the CC-BY-NC-ND 4.0 license http://creativecommons.org/licenses/by-nc-nd/4.0/ 
For sperm motility, semen was diluted in Ham's F10 culture medium to produce a concentration of about 10 to 30 million sperm $/ \mathrm{mL}$ and then analyzed routinely using the SCA CASA system previously described (Maree and van der Horst, 2013). Settings for the SCA motility module were specified for curvilinear velocity (VCL) at values of $<50>80<120 \mu \mathrm{m} / \mathrm{s}$ for slow, medium and fast sperm, respectively. The percentage fast progressive motility was set to VCL $>120 \mu \mathrm{m} / \mathrm{s}$ and straightness (STR) $>80 \%$. All motility measurements were performed at 50 frames per second for one second (50 images) with an average path velocity (VAP) setting of 7 to ensure a smoothed VAP path. The SCA system has been validated for correctly analyzing dolphin sperm. The SCA system allows replay of sperm motility tracks frame by frame (every 50th of a second) and it was possible to visually ratify correctness of sperm tracking.

\subsection{Sperm morphometrics and morphology}

Semen of the three adult dolphins was diluted in Ham's F10 and $10 \mu \mathrm{L}$ was used to make routine sperm smears. These smears represented sperm from diluted semen as well as from a routine swim-up procedure according to Maree and van der Horst (2013) and also included samples from the consecutive ejaculates. Sperm swim-up was not conducted for TT1, because of the small ejaculate volumes collected from this individual. The two methods used (semen just diluted versus swim-up) allowed sperm morphometry comparison between all sperm compared to the motile fraction only. Accordingly, the hypothesis was tested that the most motile sperm did not have different morphometrics or less abnormal sperm morphology than that of the average sample. After the sperm smears were dry, they were fixed and stained using SpermBlue according to the procedure described by van der Horst and Maree (2009). The SCA sperm morphology module was employed to analyze sperm morphometrics, which accurately measures eleven sperm morphometric features (head length $(\mu \mathrm{m})$, head width $(\mu \mathrm{m})$, head area $\left(\mu \mathrm{m}^{2}\right)$, head perimeter $(\mu \mathrm{m})$, head ellipticity, head elongation, head roughness, head regularity, midpiece width $(\mu \mathrm{m})$, midpiece insertion angle, acrosome (\%)) of each sperm. Additionally, tail length, midpiece length and total sperm length were measured separately for 100 randomly selected spermatozoa also using

(C) 2018. This manuscript version is made available under the CC-BY-NC-ND 4.0 license http://creativecommons.org/licenses/by-nc-nd/4.0/ 
the automated sperm morphology module of the SCA CASA system. The separate analysis of the head and tail morphologies has been performed because in relatively few cases a sperm component is not overlain by another part of a sperm making automated analysis of the entire sperm impossible. Only manual methods were used to score the percentage normal spermatozoa. A sperm head with an oval shape, a smooth outline and no irregularities or elongation, a small bulky midpiece (not equivalent to cytoplasmic droplet) and tail with no bends/kinks or coils were considered normal.

\subsection{Sperm ultrastructure}

Sperm of all representative ejaculates were fixed in phosphate buffered $2.5 \%$ glutaraldehyde at $4{ }^{\circ} \mathrm{C}$. Pellets formed naturally after fixation and these were processed for routine transmission electron microscopy using routine procedures (Lebelo and van der Horst, 2010, 2016, 2017). A Jeol JEM 1011 transmission electron microscope at 80 kV (Advanced Laboratory Solutions, Johannesburg, South Africa) was used to study the specimens.

\subsection{Statistical analysis}

Correlations between sperm concentrations, motility parameters and kinematic parameters were analyzed using Pearson or Spearman correlations depending on the normality distribution of the variables. Morphological parameters were compared between diluted and swim-up sperm using Student's t-test. All statistical analyses were performed in IBM SPSS, Version 23 (IBM Corp., 2015) and significance was assumed at $P \leq 0.05$.

\section{Results}

\subsection{General observations for all ejaculates}

Semen quality was in general very high for TA and TT2 but was less for TT1. In most ejaculates semen color was white and viscosity was milky but never viscous. Ejaculate volume and sperm concentrations were less for TT1 and both ejaculates appeared dilute (Table 1). Ejaculate volumes for TA and TT2 were greater than $7 \mathrm{ml}$

(C) 2018. This manuscript version is made available under the CC-BY-NC-ND 4.0 license http://creativecommons.org/licenses/by-nc-nd/4.0/ 
and about $60 \mathrm{ml}$ for TA, the largest volume obtained during the study (Table 1). Sperm concentrations were greatest in all three ejaculates from TA, whereas TT2 had minimal to moderate sperm concentrations in all three ejaculates (Table 1). Total (TM) and progressive motilities (PM) were high in all ejaculates from the three dolphins with the exception of ejaculate three from TA, in which there was the least sperm motility (Table 1). The percentage of progressively motile sperm was similar to TM in all ejaculates (Table 1). The $\mathrm{pH}$ was consistent ranging between 7 and 7.5 (Table 1).

\subsection{Results for consecutive ejaculates}

The two ejaculates from TT1 were of similar quality with $76 \%$ to $79 \%$ TM and $72 \%$ to $76 \% \mathrm{PM}$. The second ejaculate had a considerably greater sperm concentration than the first ejaculate and a smaller volume and lesser sperm motility index (SMI; Table 1). All three ejaculates from TT2 were of very high quality. Total volume, TM, PM and SMI increased successively from the first to the third ejaculate (Table 1 and Figure $1 \mathrm{~A}$ and $\mathrm{C})$. Sperm concentration was greatest in the second ejaculate, which was collected the same day as the first, and it was least in the first ejaculate in comparison to the other two ejaculates from TT2 (Table 1 and Figure 1B). Apparent hyperactivated sperm, sperm swimming in a pattern resembling a star, were observed in the first ejaculates from TT1 and TT2 (Figure 2). The first two ejaculates from TA, which were both obtained during the first day, had very high sperm concentrations, \% normal sperm morphology and SMI. The second ejaculate had the greatest sperm concentration $\left(1127 \times 10^{6} / \mathrm{ml}\right)$ of the eight ejaculates from the three bottlenose dolphins. The TM and PM were greater in the second than the first ejaculate from TA (Table 1). In contrast, the third ejaculate, which was collected on the second day, had the lowest TM, PM and SMI of any of the eight ejaculates and was much less than the first and second ejaculate, but it was the ejaculate with the largest total volume of any of the eight ejaculates (Table 1).

\subsection{Kinematics of sperm motilities}

The data for average kinematic variables, curvilinear velocity (VCL), straight-line velocity (VSL), average path velocity (VAP), linearity index (LIN), straightness of sperm

(C) 2018. This manuscript version is made available under the CC-BY-NC-ND 4.0 license http://creativecommons.org/licenses/by-nc-nd/4.0/ 
movement (STR), oscillation index (WOB), amplitude of lateral head displacement $(A L H)$ and beat cross frequency (BCF), for all motile sperm are included for the eight ejaculates in Table 2. All ejaculates contained primarily rapid sperm with a high VCL (average $V C L \geq 227 \pm 84$ ) and few sperm with a $V C L$ of less than $150 \mu \mathrm{m} / \mathrm{s}$. An example of the distribution of VCL is provided in Figure 3 for Ejaculate 3 from TT2. Differences in kinematic variables between consecutive ejaculates were observed. The VCL increased from Ejaculate 1 to 3 of TT2 and VSL, VAP, LIN, STR and WOB were least and ALH and BCF were greatest in the first ejaculates from both TT1 and TT2 (Table 2 and Figure 1D-F). The average for the kinematic variables for TA were greatest, particularly for Ejaculates 1 and 3 where the VCL, VSL, VAP, LIN, STR and WOB were high and for $\mathrm{ALH}$ and BCF were low (Table 2). Sperm concentration was positively correlated to VSL, VAP, LIN, STR and WOB $(\rho \geq 0.8, P \leq 0.02)$ and negatively with ALH $(\rho=0.8, P=$ $0.01)$ and there was a trend towards a significant negative correlation with $\operatorname{BCF}(\rho=-$ $0.7, P=0.06)$, but no correlation with $\operatorname{VCL}(\rho=0.42, P=0.3)$. Although a similar relationship appeared to exist between the percentage of total and progressive motilities and the kinematic variables, there were no significant correlations $(P \geq 0.1)$. The BCF increased with decreases in VSL, VAP $(\rho \geq-0.8, P \leq 0.03)$ and VCL, although the correlation was not significant with the latter $(\rho=-0.7, P=0.07)$. The ALH was negatively correlated with VSL, LIN, STR and WOB $(\rho \geq-0.9, P \leq 0.004)$ and there was a negative, albeit non-significant, correlation with $\operatorname{VAP}(\rho=-0.7, P=0.07)$.

Most of the sperm in all the ejaculates were either rapid non-progressive (6\%$63 \%)$ or rapid progressive (25\%-85\%) sperm and medium or slow sperm was present $\leq 13 \%$ in any of the ejaculates (Table $3 \mathrm{~A}$ ). Kinematic variables, therefore, were evaluated separately for rapid non-progressive and rapid progressive sperm. The VCL was always greater and VSL, LIN, STR and WOB were always less for rapid nonprogressive than rapid-progressive sperm (Table $3 \mathrm{~A}$ and $\mathrm{B}$ ). With TT2, there was an increase in VCL, VSL and VAP and decrease in BCF for rapid progressive sperm from the first to the third ejaculate (Table $3 A$ and $B$ ). For the other individuals and ejaculates, patterns were similar to those for average kinematic variables for all motile sperm. TA had the greatest values for VCL (rapid non-progressive, Ejaculates 1 and 3), VSL (rapid

(C) 2018. This manuscript version is made available under the CC-BY-NC-ND 4.0 license http://creativecommons.org/licenses/by-nc-nd/4.0/ 
progressive, Ejaculate 3) and VAP (rapid non-progressive, Ejaculate 3, Table 3A). For rapid progressive sperm, LIN, STR and WOB did not vary much between the eight ejaculates, but LIN and WOB were considerably less in Ejaculate 1 from TT2 than in any of the other ejaculates (Table 3B). Interestingly, VSL, VAP, LIN and WOB were less and ALH was greater for rapid non-progressive sperm (apparently hyperactivated) for the first ejaculates from TT1 and TT2 than for any of the other ejaculates and sperm categories evaluated (Table $3 \mathrm{~A}$ and $\mathrm{B}$ ).

\subsection{Sperm morphometrics}

Data are included in Table 1 for the percentage normal morphology for the three dolphins which ranged from $89 \%$ to $96 \%$. Figure 4 depicts the SCA morphometric analysis indicating accurate thresholding of the acrosome, head, midpiece and tail. Results for eleven morphometric measurements for sperm in diluted semen from all dolphins are presented in Table 4. Table 5 indicates the combined results for Ejaculates 1 and 2 after swim-up for TT2 and TA. There were no statistically significant differences $(P \geq 0.15)$ between diluted semen (Table 4 ) and swim-up sperm (motile fraction, Table 5). Sperm head length and width varied from only 4.71 to $5.04 \mu \mathrm{m}$ and 2.28 to $2.55 \mu \mathrm{m}$. The acrosome cover of the head was approximately $40 \%$ (Table 4). Total sperm length, tail length and midpiece length are shown in Table 6.

\subsection{Sperm ultrastructure}

Figure 5 depicts the main ultrastructural features of the sperm of the three dolphins. The small sperm head is partly conical and pointed anteriorly with a small acrosome (Fig. 5A). The nucleus is electron dense with clear absence of nuclear craters or fragmentation. A well-developed capitulum connected to two prominent cross-banded structures were present in the neck region of the sperm. The midpiece is particularly bulky and contains six to eight very large mitochondria that have extensive mitochondrial cristae (Figs. 5A and B). This bulky midpiece could easily be confused with one which still contains a cytoplasmic droplet. The midpiece has the typical $9+9+$ 2 arrangement surrounded by mitochondria on the outside (Fig. 5C). The outer nine

(C) 2018. This manuscript version is made available under the CC-BY-NC-ND 4.0 license http://creativecommons.org/licenses/by-nc-nd/4.0/ 
dense fibers are almost of similar form and size in transverse section, which is in contrast to most other mammals. A distinct annulus is evident marking the border between the midpiece and the principal piece (Figs. 5A and B). The principal piece typically conforms to that of other mammals containing a central axoneme surrounded by a fibrous sheath which has thickenings in positions 3 and 8 aligned with the two central doublets of the axoneme.

\section{Discussion}

The quality of ejaculates from cetaceans is generally very high with high percentage motilities and few abnormal sperm (Beilis et al., 2000; Robeck et al., 2004; Yuen et al., 2009).. Atlantic bottlenose dolphin ejaculates have been reported to be of high to very high quality with total motilities of often above $80 \%$, high viabilities and few sperm abnormalities (Robeck and O'Brien, 2004; Robeck et al., 2013; SánchezCalabuig et al., 2015), which is consistent with the findings in the present study. Ejaculate volumes and especially sperm concentrations appear to vary considerably between individual bottlenose dolphins. Average volumes of between 14 and $26 \mathrm{~mL}$ have been recorded in most studies (Robeck and O'Brien, 2004; O'Brien and Robeck, 2006; Robeck et al., 2013) and these volumes are consistent with those from the present study of an average ejaculate volume of $21 \mathrm{~mL}( \pm 14)$. Sperm concentrations were highly variable among the three dolphins as well as consecutive ejaculates in the present study, similar to previous findings of O'Brien and Robeck (2006) for five proven breeding bottlenose dolphins. The large variations may be due to individual differences in age, breeding status and captive management. Surprisingly, semen quality was not different between the $T$. truncatus and the $T$. truncates/aduncus hybrid. There was also no difference in sperm morphology, which was not surprising considering that the sperm morphology of members of the Delphinidae is very similar (Fleming et al., 1981) and the Atlantic and Indo-Pacific bottlenose dolphin are closely related. Both $T$. truncatus males sired offspring and even with the poorer sperm quality of TT1 in comparison to the other two dolphins, he sired 10 offspring in comparison to one for TT2. The relatively poor

(C) 2018. This manuscript version is made available under the CC-BY-NC-ND 4.0 license http://creativecommons.org/licenses/by-nc-nd/4.0/ 
semen quality of TT1 may be because of the advanced age of the dolphin at the time of the study.

Few studies on cetaceans investigated how sampling regimens affect sperm quality or comparative results on the quality of sperm from consecutive ejaculates. Sánchez-Calabuig et al. (2015) observed that sperm DNA fragmentation was less in the second fresh ejaculate from Atlantic bottlenose dolphins, but there was no difference in any other ejaculate and sperm variable. In contrast, in the present study there was a considerable improvement in sperm concentrations and sperm motilities in the second ejaculate of two of the dolphins. The third individual did not have enhanced sperm motilities in the second ejaculate, but an increase in sperm concentration was observed from the first to the second ejaculate. Similar trends were also observed in a study with the Indo-Pacific bottlenose dolphin, where there were greater sperm concentrations, motility and viability in the second and subsequent ejaculates compared to the first, with the first ejaculate being of a larger volume with a greater sperm count (Yuen et al., 2009). Interestingly, in the present study the ejaculate volume was largest for the third ejaculate, which was obtained a day after the first two ejaculates for two of the three dolphins (TT2 and TA), but the ejaculate quality was less for TA at the third ejaculation, while for TT2 there were greater sperm motilities, but a decrease in sperm concentration at the third ejaculation. Findings in the present study suggest that second and possibly further subsequent ejaculates contain sperm with a greater fertilizing capacity than the first ejaculate in bottlenose dolphins because of the greater number of sperm with greater motility in this ejaculate. Research on humans indicates that with a second ejaculate shortly after the first (2 to 4 hours) the second ejaculate is of greater quality in terms of sperm functionality (Alipour et al. 2017; Ayad et al. 2018b). It is speculated that within a few days sperm are detrimentally affected with the longer storage period in the distal cauda epididymis/vas deferens and that more frequent ejaculations will hence result in removal of the aged sperm. Accordingly, in multi-male mating systems and where sperm competition is greater it will be advantageous to have high sperm functionality in subsequent ejaculates.

(C) 2018. This manuscript version is made available under the CC-BY-NC-ND 4.0 license http://creativecommons.org/licenses/by-nc-nd/4.0/ 
General semen variables such as the percentage motility and sperm concentration provide for an indication of the quality of a semen sample, but ejaculates are often heterogeneous and consist of different sperm subpopulations with different functions. In this regard, the implementation of average values for the description of sperm populations often results in the loss of vital information (Holt et al., 2007; Maree and van der Horst, 2013). The CASA sperm analysis enables the categorization of such populations using kinematic variables of sperm movement and also enables the evaluation of sperm functions and the quantitative description of sperm movement patterns, such as hyperactivation (Holt et al., 2007; Maree and van der Horst, 2013).

Mean VCL, VSL and VAP are similar to the values recorded for the rapid sperm subpopulation, which is not surprising considering that most motile sperm were predominantly found to have rapidly progressive sperm motility and suggest a great level of sperm competition in Atlantic bottlenose dolphins. Studying mating strategies in marine mammals is very difficult due to the inaccessibility of the habitat, but studies have suggested that bottlenose dolphins are polygamous and females mate with several males (Wells et al., 1987). The findings with the kinematic analysis of Atlantic bottlenose dolphin sperm in the present study further support the view of a promiscuous mating system in this species.

Kinematic variables can be used to distinguish between different sperm movement patterns and characterize subpopulations accordingly. In Atlantic bottlenose dolphins, progressive sperm could be distinguished from non-progressive sperm as a result of a generally lesser VCL and ALH and greater VSL, VAP, LIN and STR.

Sperm diluted in Ham's F10 medium had sperm tracks similar to hyperactivated sperm in many mammalian species; in bottlenose dolphins these sperm tracks have relatively lesser values for VSL, VAP, LIN and WOB and greater ALH values, which can be used to characterize hyperactivated sperm in future analyses. The greater VSL, VAP and LIN values appeared to be associated with greater sperm concentrations and motilities in all ejaculates except one. Overall, it appears that when velocities and linearity of sperm movement increase, lateral head movement and beat cross frequency decrease, suggesting an inverse relationship between these variables.

(C) 2018. This manuscript version is made available under the CC-BY-NC-ND 4.0 license http://creativecommons.org/licenses/by-nc-nd/4.0/ 
Information on the normal sperm morphology of a species is as important as other aspects of semen quality to understand the reproductive biology of a species and to evaluate fertilization capabilities of fresh and cryopreserved semen. Atlantic bottlenose dolphin sperm, like all cetacean spermatozoa (Kita et al., 2001; Meisner et al., 2005), have small and short sperm heads. In comparison, the tail is long resulting in a total sperm length similar to that of many other mammals, which is also near the greatest for the order (Artiodactyla; Cummins and Woodall, 1985). Sperm head morphology of cetaceans is similar, although shorter, to that of Perissodactyla with the posterior region being thicker than the anterior component (Meisner et al., 2005). The morphological variables of head length: $\sim 5 \mu \mathrm{m}$, head width: $\sim 2.5 \mu \mathrm{m}$, total tail length: $\sim 68 \mu \mathrm{m}$ and midpiece length: $\sim 3.5 \mu \mathrm{m}$ in the present study are similar to the findings by Fleming et al. (1981) and Cummins and Woodall (1985) for Atlantic bottlenose dolphins. Other variables such as head perimeter, ellipticity, elongation, roughness and percentage acrosome coverage of the sperm head are all additional information, which describe the spermatozoa of Atlantic bottlenose dolphins in considerably more detail. In future a combination of these measurements can be used to define normal sperm morphology as has been demonstrated by van der Horst et al. (2018) in the laboratory rat. Most morphometric features have a fairly narrow distribution except for "midpiece insertion angle", which has a very wide distribution. The reason for this may be that when a sperm smear is made, most sperm are still motile and the tail insertion position may be "fixed" as the smear dries. Accordingly, the position of the anterior tail/midpiece component in relation to the head position may vary considerably depending on when motility was stopped.

Noteworthy is that the acrosome is small and covers less than half of the sperm head as was also verified by transmission electron microscopy. The midpiece in the Atlantic bottlenose dolphin might well be one of the shortest midpieces measured in mammals. The mitochondria, however, are large and mitochondrial cristae numerous possibly compensating for a short midpiece. In future cut-off values for each morphometric variable may assist to quantify the percentage sperm morphology using CASA. In most other Artiodactyla, the midpiece length is well over $10 \mu \mathrm{m}$ and also other

(C) 2018. This manuscript version is made available under the CC-BY-NC-ND 4.0 license http://creativecommons.org/licenses/by-nc-nd/4.0/ 
mammals seldom have midpiece lengths of less than $5 \mu \mathrm{m}$ (Cummins and Woodall, 1985; Anderson et al., 2005). The midpiece in bottlenose dolphin sperm is, however, very bulky and the volume, calculated using the volume for a cylinder, is about $3.2 \mu \mathrm{m}^{3}$ and much larger than in other Artiodactyla (dolphins are categorized in the infra order Cetacea, one of the orders of the clade Artiodactyla) (Anderson et al., 2005). Anderson et al. (2005) found that there is a relationship between the sperm midpiece volume and the mating system of a species with volumes being larger in species with multiple mates and suggested that this is due to a larger number of mitochondria packed into the midpiece to improve swimming speeds. Six to eight very large mitochondria with extensive cristae are found in the midpiece of the Atlantic bottlenose dolphin, which likely enable the spermatozoa to swim at the high speeds as observed in the present study and further support a multi-male mating system for this species. This observation does not negate additional energy provided for motility by means of glycolysis.

In conclusion, Atlantic bottlenose dolphin ejaculates are of exceptionally high quality with high sperm concentrations, high motilities and few abnormal sperm. Further, semen quality is greater with the second ejaculate than the first and future studies should consider collecting more than one ejaculate to obtain the greatest quality semen possible, particularly for cryo-preservation purposes or fresh samples for IVF. Most of the motile sperm move at very high velocities and very few sperm have a VCL below $150 \mu \mathrm{m} / \mathrm{s}$ at 50 frames per second analysis, making these sperm subpopulations almost negligible. In addition, from the results of the present study different sperm subpopulations can be characterized by the specific kinematic variables. The spermatozoa have small heads, but long tails and although surprisingly short, the midpiece is very bulky with few large mitochondria and abundant cristae mitochondrialis. The high quality of ejaculated sperm, large number of very fast swimming sperm and bulky midpiece all support a multi-male mating system in the Atlantic bottlenose dolphin and are likely adaptions to the high sperm competition associated with this mating system (van der Horst and Maree, 2014).

(C) 2018. This manuscript version is made available under the CC-BY-NC-ND 4.0 license http://creativecommons.org/licenses/by-nc-nd/4.0/ 


\section{Acknowledgement}

We are grateful to The South African Association for Marine Biological Research (SAAMBR) that incorporates uShaka Sea World for allowing us to do this study on their dolphins. Our sincere appreciation to the staff and in particular the dolphin trainers and veterinarians for their assistance and guidance with semen collections. T. Musekwa and T.S. Rathanya from the National Zoological Gardens of South Africa (NZG) are thanked for their laboratory assistance. Ms Nolan Muller of the National Health Laboratories are thanked for assistance with transmission electron microscopy. Prof Antoinette Kotze of the NZG, Pretoria assisted in obtaining permission from uShaka to publish this paper and also for reading the manuscript critically. The project was partly funded by the Wildlife Biological Resource Centre through a core grant received from the Department of Science and Technology. Consumables and the SCA CASA system were provided by the University of the Western Cape, Bellville, South Africa.

\section{Conflict of interest}

The authors declare no conflicts of interest. $G$ van der Horst is a senior consultant to Microptic. We used their SCA CASA system, but there is no conflict of interest in the context with this paper.

(C) 2018. This manuscript version is made available under the CC-BY-NC-ND 4.0 license http://creativecommons.org/licenses/by-nc-nd/4.0/ 


\section{References}

Alipour, H., van der Horst, G., Christiansen, O.B., Dardmeh, F., Jørgensen, N., Nielsen, H.I., Hnida, C., 2017. Improved sperm kinematics in semen samples collected after $2 \mathrm{~h}$ versus 4-7 days of ejaculation abstinence. Hum. Reprod. 32, 1364-1372.

Ambriz, D., Rosales, A.M., Sotelo, R., Mora, J.A., Rosado, A., García, J.A., Rosado, A., García, A.R., 2002. Changes in the quality of rabbit semen in 14 consecutive ejaculates obtained every 15 minutes. Arch. Androl. 48, 389-395.

Anderson, M.J., Nyholt, J., Dixson, A.F., 2005. Sperm competition and the evolution of sperm midpiece volume in mammals. J. Zool. (Lond.) 267, 135-142.

Ayad, B.M., van der Horst, G., du Plessis, S.S., 2018a. Revisiting the relationship between the ejaculatory abstinence period and semen characteristics. Int. J. Fertil. Steril. 11, 238-246.

Ayad, B.M., van der Horst, G., du Plessis, S.S., 2018b. Short abstinence: A potential strategy for the improvement of sperm quality. Middle East Fertil. Soc. J. 23, 37-43.

Beilis, A., Cetica, P., Merani, M.S., 2000. Sperm morphology and morphometry of Burmeister's porpoise (Phocoena spinipinnis). Mar. Mammal Sci. 16, 636-639.

Cummins, J.M., Woodall, P.F., 1985. On mammalian sperm dimensions. J. Reprod. Fertil. 75, 153-175.

Fleming, A.D., Yanagimachi, R., Yanagimachi, H., 1981. Spermatozoa of the Atlantic bottlenosed dolphin, Tursiops truncatus. J. Reprod. Fertil. 63, 509-514.

Holt, W. V., O'Brien, J., Abaigar, T., 2007. Applications and interpretation of computerassisted sperm analyses and sperm sorting methods in assisted breeding and comparative research. Reprod. Fertil. Dev. 19, 709-718.

Kita, S., Yoshioka, M., Kashiwagi, M., Ogawa, S., Tobayama, T., 2001. Comparative external morphology of cetacean spermatozoa. Fish. Sci. 67, 482-492.

Lebelo, S.L., van der Horst, G., 2010. The ultrastructure of the Sertoli cell of the vervet monkey, Chlorocebus aethiops. Tissue Cell 42, 348-354.

Lebelo, S.L., van der Horst, G., 2016. Ultrastructural changes occurring during spermiogenesis of the vervet monkey, Chlorocebus aethiops. Asian J. Anim. Sci.

(C) 2018. This manuscript version is made available under the CC-BY-NC-ND 4.0 license http://creativecommons.org/licenses/by-nc-nd/4.0/ 
10, 247-254.

Lebelo, S.L., van der Horst, G., 2017. Histological and ultrastructural features of the Leydig cells and their association with other testicular cells of the vervet monkey, Chlorocebus aethiops. Pak. J. Zool. 49, 1595-1601.

Maree, L., van der Horst, G., 2013. Quantification and identification of sperm subpopulations using computer-aided sperm analysis and species-specific cut-off values for swimming speed. Biotech. Histochem. 88, 181-193.

Meisner, A.D., Klaus, A. V, O'Leary, M.A., 2005. Sperm head morphology in 36 species of Artiodactylans, Perissodactylans, and Cetaceans (Mammalia). J. Morphol. 263, 179-202.

Montano, G.A., Kraemer, D.C., Love, C.C., Robeck, T.R., O'Brien, J.K., 2012. Evaluation of motility, membrane status and DNA integrity of frozen-thawed bottlenose dolphin (Tursiops truncatus) spermatozoa after sex-sorting and recryopreservation. Reproduction 143, 799-813.

O'Brien, J.K., Robeck, T.R., 2006. Development of sperm sexing and associated assisted reproductive technology for sex preselection of captive bottlenose dolphins (Tursiops truncatus). Reprod. Fertil. Dev. 18, 319-329.

O'Brien, J.K., Robeck, T.R., 2010a. Preservation of beluga (Delphinapterus leucas) spermatozoa using a trehalose-based cryodiluent and directional freezing technology. Reprod. Fertil. Dev. 22, 653-663.

O'Brien, J.K., Robeck, T.R., 2010b. The value of ex situ cetacean populations in understanding reproductive physiology and developing assisted reproductive technology for ex situ and in situ species management and conservation efforts. Int. J. Comp. Psychol. 23, 227-248.

O'Brien, J.O., Steinman, K.J., Schmitt, T., Robeck, T.R., 2008. Semen collection, characterisation and artificial insemination in the beluga (Delphinapterus leucas) using liquid-stored spermatozoa. Reprod. Fertil. Dev. 20, 770-783.

Reeves, R.R., Smith, B.D., Crespo, E.A., Notarbartolo di Sciara, G., (compilers), 2003. Dolphins, Whales and Porpoises: 2002-2010 Conservation Action Plan for the World's Cetaceans. IUCN/SSC Cetacean Specialist Group, IUCN, Gland,

(C) 2018. This manuscript version is made available under the CC-BY-NC-ND 4.0 license http://creativecommons.org/licenses/by-nc-nd/4.0/ 
Switzerland and Cambridge, UK: International Union for Conservation of Nature and Natural Resources (IUCN), 139 pp.

Ritar, A.J., Mendoza, G., Salamon, S., White, I.G., 1992. Frequent semen collection and sperm reserves of the male Angora goat (Capra hircus). J. Reprod. Fertil. 95, 97102.

Robeck, T.R., Montano, G.A., Steinman, K.J., Smolensky, P., Sweeney, J., Osborn, S., O'Brien, J.K., 2013. Development and evaluation of deep intra-uterine artificial insemination using cryopreserved sexed spermatozoa in bottlenose dolphins (Tursiops truncatus). Anim. Reprod. Sci. 139, 168-181.

Robeck, T.R., O'Brien, J.K., 2004. Effect of cryopreservation methods and precryopreservation storage on bottlenose dolphin (Tursiops truncatus) spermatozoa. Biol. Reprod. 70, 1340-1348.

Robeck, T.R., Steinman, K.J., Gearhart, S., Reidarson, T.R., McBain, J.F., Monfort, S.L., 2004. Reproductive physiology and development of artificial insemination technology in killer whales (Orcinus orca). Biol. Reprod. 71, 650-660.

Robeck, T.R., Steinman, K.J., Greenwell, M., Ramirez, K., Van Bonn, W., Yoshioka, M., Katsumata, E., Dalton, L., Osborn, S., O’Brien, J.K., 2009. Seasonality, estrous cycle characterization, estrus synchronization, semen cryopreservation, and artificial insemination in the Pacific white-sided dolphin (Lagenorhynchus obliquidens). Reproduction 138, 391-405.

Sánchez-Calabuig, M.J., López-Fernández, C., Johnston, S.S.D.S., Blyde, D., Cooper, J., Harrison, K., de la Fuente, J., Gosálvez, J., 2015. Effect of cryopreservation on the sperm DNA fragmentation dynamics of the bottlenose dolphin (Tursiops truncatus). Reprod. Domest. Anim. 50, 227-235.

van der Horst, G., Maree, L., 2009. SpermBlue®: A new universal stain for human and animal sperm which is also amenable to automated sperm morphology analysis. Biotech. Histochem. 84, 299-308.

Van der Horst, G., Maree, L., 2014. Sperm form and function in the absence of sperm competition. Mol. Reprod. Dev. 81, 204-216.

van der Horst, G., Skosana, B., Legendre, A., Oyeyipo, P., du Plessis, S.S., 2018. Cut-

(C) 2018. This manuscript version is made available under the CC-BY-NC-ND 4.0 license http://creativecommons.org/licenses/by-nc-nd/4.0/ 
off values for normal sperm morphology and toxicology for automated analysis of rat sperm morphology and morphometry. Biotech. Histochem. 93, 49-58.

Wells, R.S., Scott, M.D., Irvine, A.B., 1987. The social structure of free-ranging bottlenose dolphins, in: Genoways, H.H. (eds), Current Mammalogy. Springer, Boston, MA, pp. 247-305.

Yuen, Q.W.H., Brook, F.M., Kinoshita, R.E., Ying, M.T.C., 2009. Semen collection and ejaculate characteristics in the Indo-Pacific bottlenose dolphin (Tursiops aduncus). J. Androl. 30, 432-439.

(C) 2018. This manuscript version is made available under the CC-BY-NC-ND 4.0 license http://creativecommons.org/licenses/by-nc-nd/4.0/ 


\section{Figure legends}

Fig. 1. Ejaculate characteristics (volume (A), sperm concentration (B), percentage motile sperm $(C)$ ) and sperm motility characteristics (curvilinear velocity $(D)$, straight-line velocity $(E)$, straightness of sperm movement $(F))$ of three consecutive ejaculates from one bottlenose dolphin (TT2). Data presented as mean \pm standard deviation (D-F).

Fig. 2. Motility analysis showing apparently hyperactivated sperm in the first ejaculate obtained from TT2. Blue - slow non-progressive, Green - non-progressive, Red progressive, Yellow circle - Immotile.

Fig. 3. Distribution of sperm numbers for different degrees of curvilinear velocity (50-75, 75-100, 100-125, 125-150 and >150 $\mu \mathrm{m} / \mathrm{s}$; VCL). Results are shown for one bottlenose dolphin only (TT2, ejaculate 3 ) and no motile sperm below 50 VCL were observed.

Fig. 4. Three bottlenose dolphin spermatozoa stained with SpermBlue (Top) and automated SCA morphology analysis of same three sperm showing the acrosome (yellow), rest of head (blue), midpiece (green) and rest of tail in yellow (all parts not in proportion).

Fig. 5. Ultrastructural features of Atlantic bottlenose dolphin sperm showing the sperm head with acrosome (A) and midpiece (longitudinal (B) and transverse (C)).

(C) 2018. This manuscript version is made available under the CC-BY-NC-ND 4.0 license http://creativecommons.org/licenses/by-nc-nd/4.0/ 


\section{Table 1}

Macro characteristics and percentage motilities of ejaculates from three bottlenose dolphins (Tursiops truncatus). Two to three consecutive ejaculates were obtained and immediately evaluated after ejaculation. Ejaculates marked with * were collected on the same day.

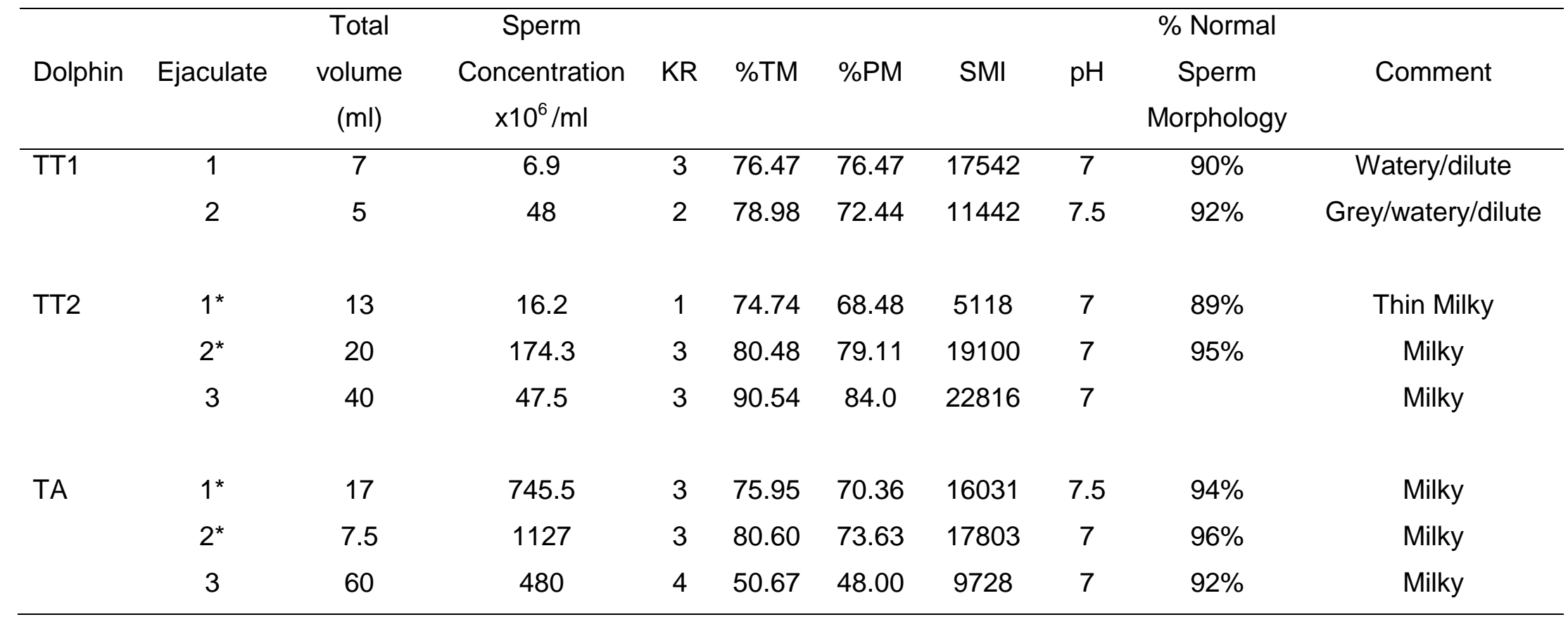

KR - Kinetic Rating was graded subjectively as follows: $0=$ no movement; $5=$ rapid, steady forward progression, \%TM -

Percentage total motility, \%PM - Percentage progressive motility, Sperm Motility Index: SMI = \%TM X \%PM X KR

(C) 2018. This manuscript version is made available under the CC-BY-NC-ND 4.0 license

http://creativecommons.org/licenses/by-nc-nd/4.0/ 


\section{Table 2}

Kinematic variables for all motile sperm from two to three consecutive ejaculates obtained from three bottlenose dolphins

\begin{tabular}{lccccccccc}
\hline Dolphin & Ejaculate & VCL $(\mu m / s)$ & VSL $(\mu m / s)$ & VAP $(\mu m / s)$ & LIN $(\%)$ & STR $(\%)$ & WOB $(\%)$ & ALH $(\mu m)$ & BCF $(\mathrm{Hz})$ \\
\hline TT1 & 1 & $291.7 \pm 88.4$ & $121.7 \pm 102.4$ & $212.9 \pm 85.5$ & $43.2 \pm 35.5$ & $52.5 \pm 33.5$ & $73.3 \pm 20.2$ & $5.1 \pm 2.9$ & $17.4 \pm 6.4$ \\
& 2 & $239.6 \pm 89.6$ & $181.3 \pm 96.0$ & $214.3 \pm 91.4$ & $73.6 \pm 25.7$ & $82.1 \pm 23.2$ & $87.4 \pm 13.3$ & $2.9 \pm 1.2$ & $16.1 \pm 7.6$ \\
& & & & & & & & \\
TT2 & 1 & $227.2 \pm 84.4$ & $112.1 \pm 69.8$ & $159.3 \pm 64.3$ & $51.1 \pm 27.6$ & $68.1 \pm 28.3$ & $71.1 \pm 18.2$ & $4.1 \pm 2.2$ & $17.6 \pm 8.8$ \\
& 2 & $261.4 \pm 84.4$ & $229.6 \pm 83.9$ & $252.4 \pm 84.7$ & $88.0 \pm 16.9$ & $91.1 \pm 15.4$ & $96.1 \pm 7.0$ & $2.4 \pm 0.8$ & $16.5 \pm 7.4$ \\
& 3 & $274.5 \pm 86.8$ & $203.4 \pm 94.6$ & $244.3 \pm 87.4$ & $73.4 \pm 25.6$ & $81.9 \pm 22.7$ & $87.6 \pm 13.9$ & $3.1 \pm 1.4$ & $14.2 \pm 8.4$ \\
& & & & & & & & \\
TA & 1 & $304.4 \pm 100.3$ & $233.9 \pm 110.4$ & $281.2 \pm 102.8$ & $76.4 \pm 25.3$ & $82.6 \pm 22.6$ & $91.1 \pm 11.9$ & $3.0 \pm 1.3$ & $12.7 \pm 7.5$ \\
& 2 & $268.5 \pm 109.4$ & $228.6 \pm 117.5$ & $256.7 \pm 113.5$ & $82.4 \pm 24.6$ & $87.1 \pm 22.6$ & $92.7 \pm 13.7$ & $2.5 \pm 0.9$ & $15.7 \pm 8.0$ \\
& 3 & $310.0 \pm 99.8$ & $284.1 \pm 103.9$ & $304.0 \pm 101.9$ & $90.5 \pm 13.1$ & $92.8 \pm 11.5$ & $97.3 \pm 4.4$ & $2.5 \pm .07$ & $13.8 \pm 8.2$
\end{tabular}

Data presented as mean \pm standard deviation. VCL - Curvilinear velocity, VSL - Straight-line velocity, VAP - Average pathway velocity, LIN - Linearity index, STR - Straightness of sperm movement, WOB - Oscillation index, ALH Amplitude of lateral head displacement, BCF - Beat cross frequency 


\section{Table 3A}

Percentage motilities for rapid, medium and slow non-progressive (NPM) and progressive sperm (PM) and kinematics (VCL, VSL, VAP: Table 3A and LIN, STR, WOB, ALH, BCF: Table 3B) of rapid NP and P sperm of two to three consecutive ejaculates from three individual bottlenose dolphins

\begin{tabular}{|c|c|c|c|c|c|c|c|c|c|}
\hline \multirow[b]{2}{*}{ Dolphin } & \multirow[b]{2}{*}{ Ejaculate } & \multirow{2}{*}{$\begin{array}{c}\text { \%NPM } \\
\text { Rapid:Medium: } \\
\text { Slow }\end{array}$} & \multirow{2}{*}{$\begin{array}{c}\text { \%PM } \\
\text { Rapid:Medium: } \\
\text { Slow }\end{array}$} & \multicolumn{2}{|c|}{$\mathrm{VCL}(\mu \mathrm{m} / \mathrm{s})$} & \multicolumn{2}{|c|}{ VSL $(\mu \mathrm{m} / \mathrm{s})$} & \multicolumn{2}{|c|}{$\operatorname{VAP}(\mu m / s)$} \\
\hline & & & & Rapid NP & Rapid P & Rapid NP & Rapid P & Rapid NP & Rapid P \\
\hline \multirow{4}{*}{ TT1 } & \multirow{2}{*}{$1^{\#}$} & \multirow{2}{*}{$63: 0: 0$} & \multirow{2}{*}{ 25:13:0 } & $301.0 \pm$ & $268.6 \pm$ & $67.4 \pm$ & $257.4 \pm$ & 192.1土 & $264.8 \pm$ \\
\hline & & & & 94.5 & 83.2 & 48.8 & 81.3 & 81.3 & 84.3 \\
\hline & \multirow{2}{*}{2} & \multirow{2}{*}{$24: 4: 3$} & \multirow{2}{*}{$60: 6: 2$} & $274.1 \pm$ & $261.1 \pm$ & $128.1 \pm$ & 233.3 \pm & $231.4 \pm$ & $242.4 \pm$ \\
\hline & & & & 77.9 & 71.2 & 65.8 & 76.1 & 79.6 & 74.8 \\
\hline \multirow{6}{*}{ TT2 } & \multirow{2}{*}{$1^{\#}$} & \multirow{2}{*}{$47: 3: 4$} & \multirow{2}{*}{$38: 7: 2$} & $257.1 \pm$ & $242.5 \pm$ & $79.1 \pm$ & $175.8 \pm$ & $164.4 \pm$ & $189.2 \pm$ \\
\hline & & & & 66.9 & 71.8 & 47.0 & 54.5 & 52.8 & 55.1 \\
\hline & \multirow{2}{*}{2} & \multirow{2}{*}{ 11:0.3:1 } & \multirow{2}{*}{$83: 3: 1$} & $305.6 \pm$ & $266.6 \pm$ & $164.4 \pm$ & $249.0 \pm$ & $284.9 \pm$ & $259.6 \pm$ \\
\hline & & & & 82.2 & 74.8 & 82.2 & 70.8 & 84.3 & 74.7 \\
\hline & \multirow{2}{*}{3} & \multirow{2}{*}{$29: 2: 3$} & \multirow{2}{*}{$62: 2: 2$} & $300.2 \pm$ & $288.2 \pm$ & $137.6 \pm$ & $255.1 \pm$ & $249.8 \pm$ & $267.1 \pm$ \\
\hline & & & & 65.1 & 70.9 & 60.6 & 68.1 & 70.0 & 69.7 \\
\hline \multirow{6}{*}{$\mathrm{TA}$} & \multirow{2}{*}{1} & \multirow{2}{*}{$26: 1: 3$} & \multirow{2}{*}{$65: 3: 2$} & $348.8 \pm$ & $315.2 \pm$ & $158.2 \pm$ & $288.2 \pm$ & $303.8 \pm$ & $300.1 \pm$ \\
\hline & & & & 70.1 & 81.4 & 67.4 & 86.8 & 76.2 & 87.1 \\
\hline & \multirow{2}{*}{2} & \multirow{2}{*}{$12: 2: 3$} & \multirow{2}{*}{$73: 6: 4$} & $305.4 \pm$ & $296.2 \pm$ & $123.7 \pm$ & $278.6 \pm$ & $281.0 \pm$ & $288.6 \pm$ \\
\hline & & & & 93.6 & 89.7 & 81.3 & 88.6 & 90.6 & 91.7 \\
\hline & \multirow{2}{*}{3} & \multirow{2}{*}{$6: 1: 2$} & \multirow{2}{*}{$85: 4: 1$} & $349.2 \pm$ & $328.4 \pm$ & 194.6士 & $311.4 \pm$ & $330.8 \pm$ & $323.5 \pm$ \\
\hline & & & & 69.4 & 79.7 & 70.1 & 82.1 & 72.3 & 82.4 \\
\hline
\end{tabular}

(C) 2018. This manuscript version is made available under the CC-BY-NC-ND 4.0 license http://creativecommons.org/licenses/by-nc-nd/4.0/ 
Table 3B

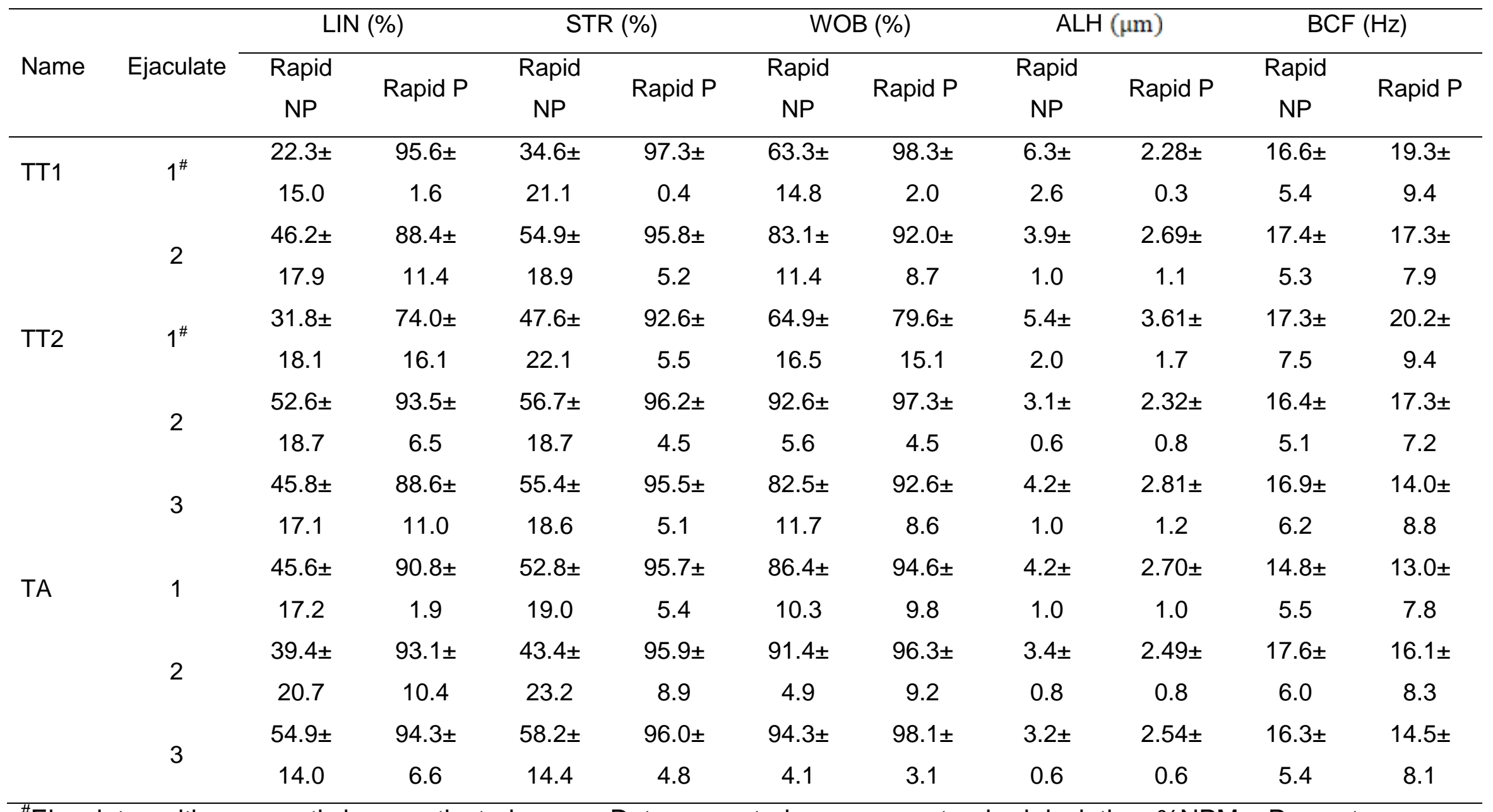

"Ejaculates with apparently hyperactivated sperm. Data presented as mean \pm standard deviation. \%NPM - Percentage non-progressive sperm, \%PM - Percentage progressive sperm, VCL - Curvilinear velocity, VSL - Straight-line velocity,

(C) 2018. This manuscript version is made available under the CC-BY-NC-ND 4.0 license http://creativecommons.org/licenses/by-nc-nd/4.0/ 
VAP - Average pathway velocity, LIN - Linearity index, STR - Straightness of sperm movement, WOB - Oscillation index, ALH - Amplitude lateral head movement, BCF - Beat cross frequency

(C) 2018. This manuscript version is made available under the CC-BY-NC-ND 4.0 license http://creativecommons.org/licenses/by-nc-nd/4.0/ 


\section{Table 4}

Morphometric parameters of sperm in semen diluted for three dolphins (average $\pm S D$ ) as determined through automated SCA morphology analysis using SpermBlue stain. Consecutive ejaculates combined.

\begin{tabular}{lcccccc}
\hline Morphometric parameters & \multicolumn{2}{c}{ TT1 } & \multicolumn{2}{c}{ TT2 } & \multicolumn{2}{c}{ TA } \\
\hline Head length $(\mu \mathrm{m})$ & 4.92 & 0.28 & 5.04 & 0.28 & 4.71 & 0.35 \\
Head width $(\mu \mathrm{m})$ & 2.23 & 0.12 & 2.55 & 0.14 & 2.28 & 0.12 \\
Head area $\left(\mu \mathrm{m}^{2}\right)$ & 9.21 & 0.68 & 10.74 & 0.85 & 9.14 & 0.90 \\
Head perimeter $(\mu \mathrm{m})$ & 12.44 & 0.55 & 13.14 & 0.59 & 12.13 & 0.68 \\
Head ellipticity & 2.22 & 0.17 & 1.99 & 0.15 & 2.07 & 0.15 \\
Head elongation & 0.38 & 0.03 & 0.33 & 0.03 & 0.35 & 0.03 \\
Head roughness & 0.75 & 0.03 & 0.78 & 0.03 & 0.78 & 0.02 \\
Head regularity & 0.93 & 0.03 & 0.94 & 0.02 & 0.93 & 0.03 \\
Midpiece width $(\mu \mathrm{m})$ & 1.05 & 0.37 & 1.07 & 0.35 & 1.17 & 0.20 \\
Midpiece insertion angle & 5.37 & 3.08 & 9.45 & 11.38 & 6.47 & 4.51 \\
Acrosome $(\%)$ & 42.37 & 3.21 & 38.80 & 3.81 & 40 & 4.81 \\
\hline
\end{tabular}

(C) 2018. This manuscript version is made available under the CC-BY-NC-ND 4.0 license http://creativecommons.org/licenses/by-nc-nd/4.0/ 


\section{Table 5}

Morphometric variables of sperm from swim-up samples (motile fraction) of first and second ejaculates combined (average $\pm S D$ ) as determined through automated SCA morphology analysis.

\begin{tabular}{lcccc}
\hline Morphometric variables & \multicolumn{2}{c}{ TT2 } & \multicolumn{2}{c}{ TA } \\
\hline Head length $(\mu \mathrm{m})$ & 4.93 & 0.41 & 5.08 & 0.24 \\
Head width $(\mu \mathrm{m})$ & 2.61 & 0.20 & 2.55 & 0.13 \\
Head area $\left(\mu \mathrm{m}^{2}\right)$ & 10.81 & 1.38 & 11.03 & 0.83 \\
Head perimeter $(\mu \mathrm{m})$ & 13.03 & 1.07 & 13.28 & 0.54 \\
Head ellipticity & 1.89 & 0.14 & 1.99 & 0.11 \\
Head elongation & 0.31 & 0.03 & 0.33 & 0.03 \\
Head roughness & 0.80 & 0.03 & 0.78 & 0.02 \\
Head regularity & 0.94 & 0.04 & 0.93 & 0.02 \\
Midpiece width $(\mu \mathrm{m})$ & 1.03 & 0.38 & 1.09 & 0.34 \\
Midpiece insertion angle & 7.02 & 8.95 & 6.45 & 5.56 \\
Acrosome $(\%)$ & 42.5 & 5.03 & 45.1 & 3.26 \\
\hline
\end{tabular}

(C) 2018. This manuscript version is made available under the CC-BY-NC-ND 4.0 license http://creativecommons.org/licenses/by-nc-nd/4.0/ 
Table 6

Tail length, midpiece length and total sperm length for 100 sperm randomly selected from all three dolphins and swim-up samples.

\begin{tabular}{cc}
\hline Morphology variable & Average $( \pm \mathrm{SD})$ \\
\hline Tail length $(\mu \mathrm{m})$ & $67.7( \pm 5.7)$ \\
Midpiece length $(\mu \mathrm{m})$ & $3.48( \pm 0.32)$ \\
Total sperm length $(\mu \mathrm{m})$ & $72.7( \pm 5.3)$ \\
\hline
\end{tabular}

(C) 2018. This manuscript version is made available under the CC-BY-NC-ND 4.0 license http://creativecommons.org/licenses/by-nc-nd/4.0/ 

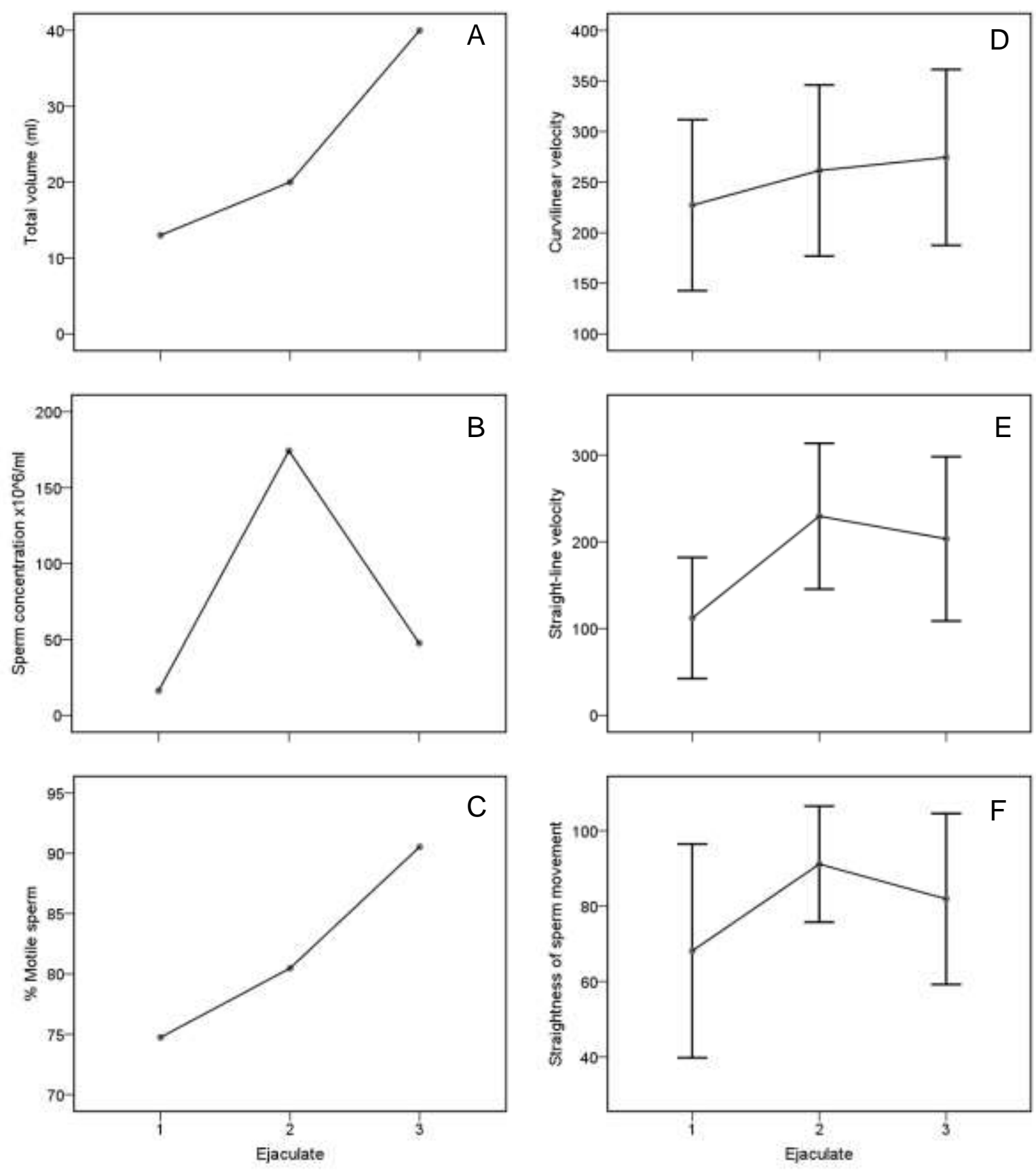

Figure 1. http://creativecommons.org/licenses/by-nc-nd/4.0/ 


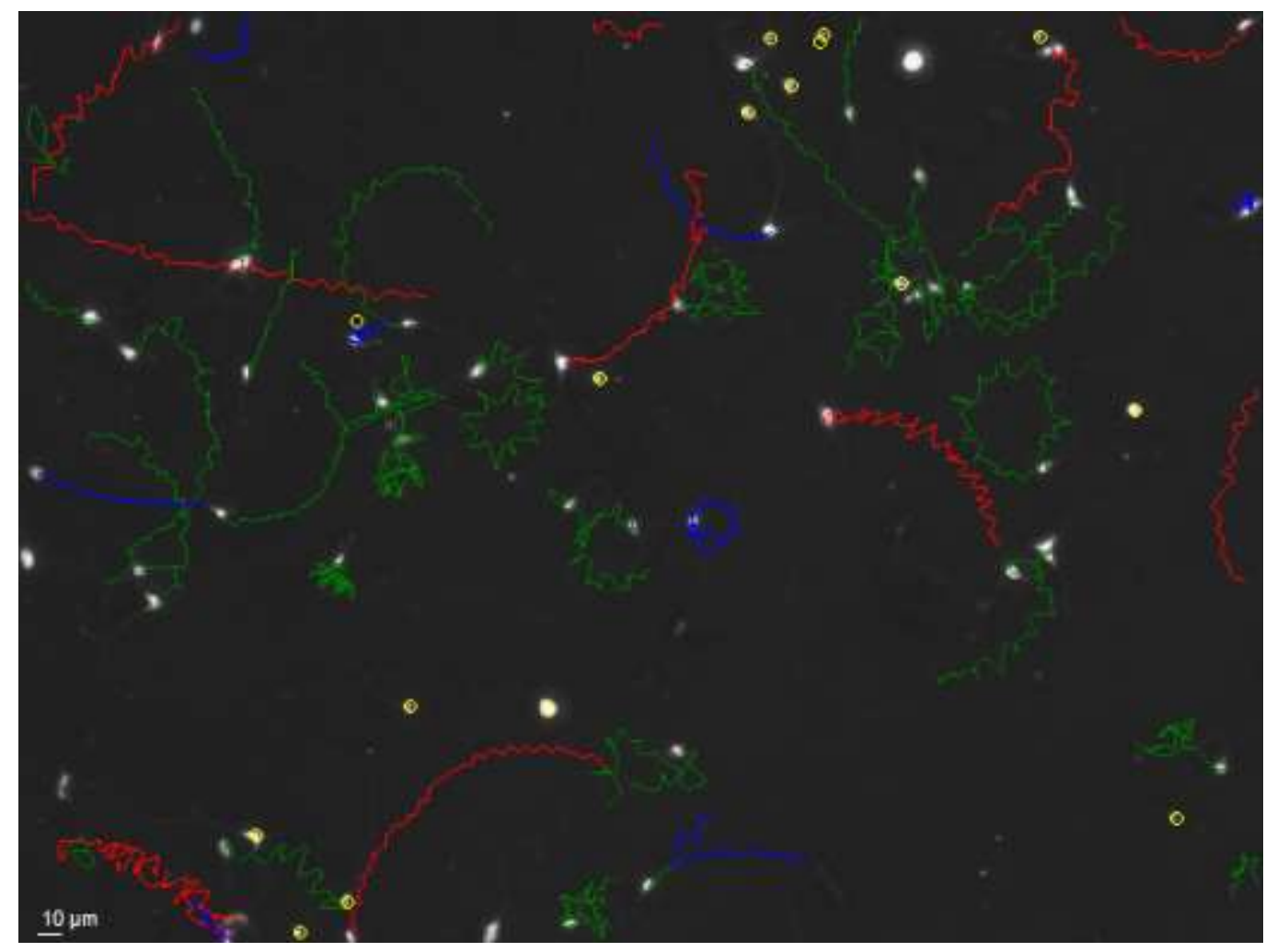

Figure 2.

(C) 2018. This manuscript version is made available under the CC-BY-NC-ND 4.0 license http://creativecommons.org/licenses/by-nc-nd/4.0/ 


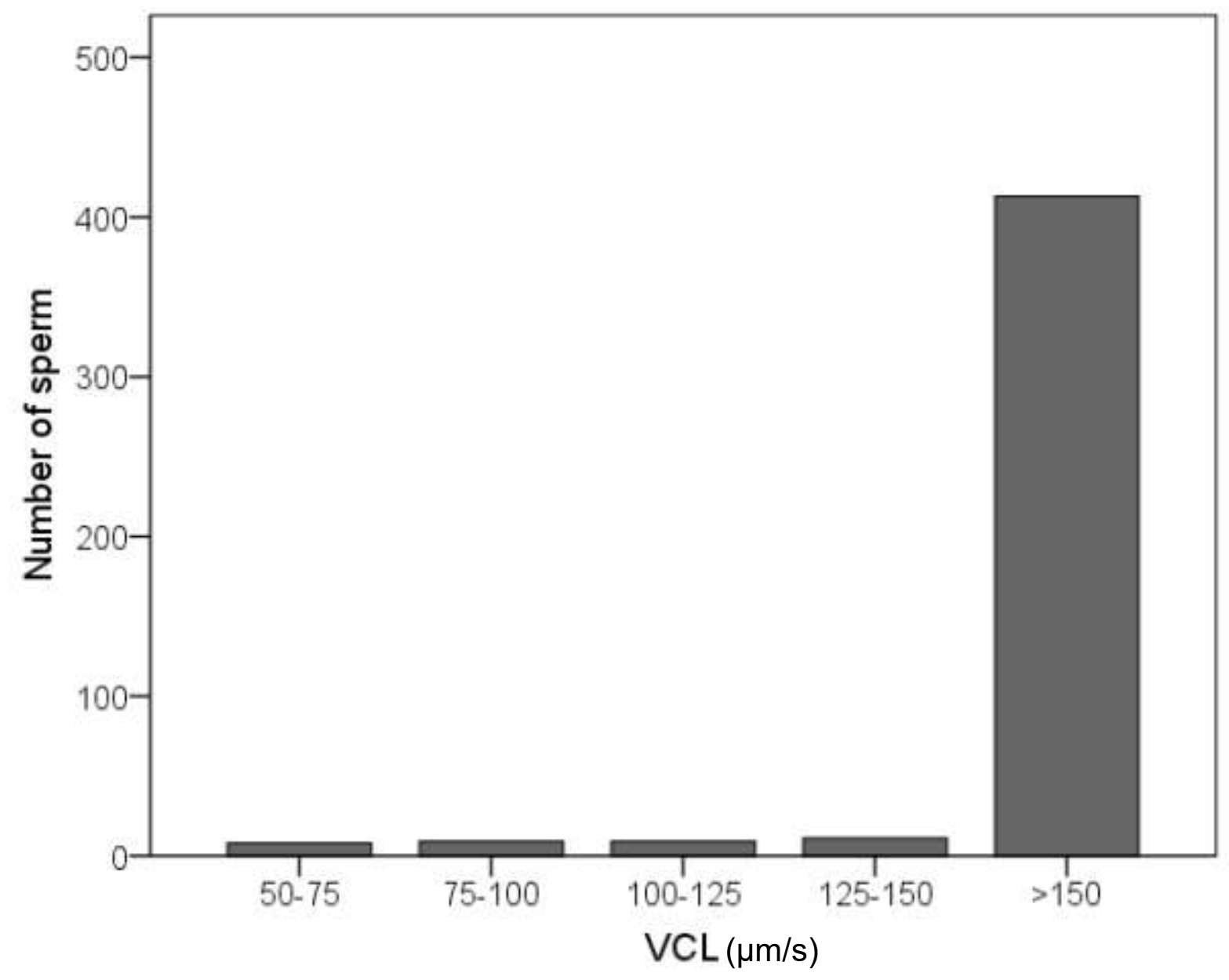

Figure 3.

(C) 2018. This manuscript version is made available under the CC-BY-NC-ND 4.0 license http://creativecommons.org/licenses/by-nc-nd/4.0/ 


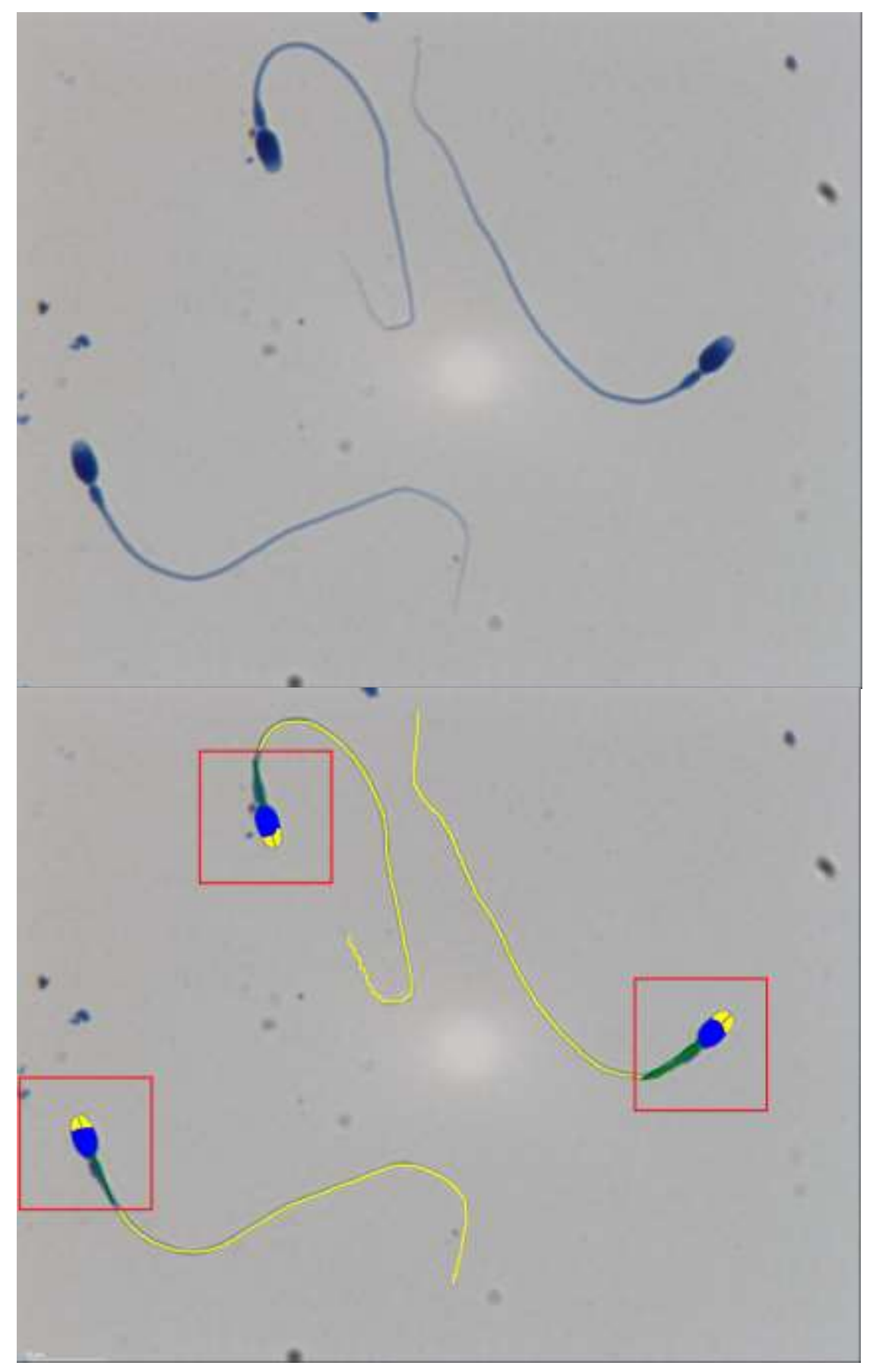

Figure 4.

(C) 2018. This manuscript version is made available under the CC-BY-NC-ND 4.0 license http://creativecommons.org/licenses/by-nc-nd/4.0/ 